\title{
Proceeding
}

Supplementary Issue: Spring Conferences of Sports Science. 15th Convention and Workshop of the International Network of Sport and Health Science, 5-8 June 2019. University of Las Palmas de Gran Canaria, Las Palmas de Gran Canaria, Spain.

\section{Back pain start with physical activity}

\author{
ILARIA MACRII 1 , ALFREDO PIO DI TORE², SIMONA FATTORE ${ }^{1}$ \\ ${ }^{1}$ University of Salerno, Italy \\ 2University of Foggia, Italy
}

\begin{abstract}
The Back Pain is the most frequent osteoarticular disorder, representing, after the common cold, the most frequent human disease. Nearly $80 \%$ of the population is destined for a certain point of life to an entire low back pain. It affects men and women equally; it occurs more often between 30 and 50 years of age; it involves very high individual and social costs, in terms of diagnostic analyses and treatments, reduction in productivity and capacity to carry out daily activities. Over $95 \%$ of the problems have a mechanical cause underlying low back pain. The most common causes are the degenerative processes related to eternity in the intervertebral discs and in the facet joints. The aim is, through a survey with a questionnaire, to highlight the differences between subjects who practice physical activity, non-practicing and subjects who attend a postural back gymnastics course. The results show that the subjects subjected to the test, and who practice physical activity, suffer from back pain rarely (61\%), the sedentary suffer from it sometimes $(50 \%)$ and usually $(50 \%)$. In conclusion, it was shown that the best form of prevention of back pain is physical exercise. The practice of a sport adapted to age and physical conditions serves to maintain good muscle tone, to safeguard bone structures. The sport practice is also useful to learn the correct movements during everyday life such as knowing how to lift a weight correctly from the ground or assume a correct posture. Keywords: Survey; Movement, Hypokinesia.
\end{abstract}

\section{Cite this article as:}

Macrì, I., Di Tore, A.P., \& Fattore, S. (2019). Back pain start with physical activity. Journal of Human Sport and Exercise, 14(4proc), S624-S630. doi:https://doi.org/10.14198/hse.2019.14.Proc4.21

Corresponding author. University of Salerno, Italy.

E-mail: i.macri@studenti.unisa.it

Supplementary Issue: Spring Conferences of Sports Science. 15th Convention and Workshop of the International Network of Sport and Health Science, 5-8 June 2019. University of Las Palmas de Gran Canaria, Las Palmas de Gran Canaria, Spain. JOURNAL OF HUMAN SPORT \& EXERCISE ISSN 1988-5202

(c) Faculty of Education. University of Alicante

doi:10.14198/jhse.2019.14.Proc4.21 


\section{INTRODUCTION}

The back pain is the most frequent osteoarticular disorder, representing, after the common cold, the most frequent human disease (Zhou et al., 2019, Murillo et al., 2019). The human back is composed of a complex structure of muscles, ligaments, tendons, disks, and bones, which work together to support the body and enable us to move around. The movement can combat the back pain? (Avman et al., 2019, Fewster et al., 2019, Gallagher et al., 2019). The specific academic training on exercise and sport sciences could give a contribution on the issue (D'elia, 2019, Sanseviero et al, 2019,) because it is the fundamental basis of the scientific identity of physical activity (Tiziana, 2019, Raiola et al., 2018). In the same time, also the childhood and primary physical education (Valentini et al., 2018, Ceciliani, 2018, D'Isanto, 2016, Altavilla, Di Tore, 2016, Di Tore et al., 2016, Ceciliani et al., 2015). Nearly $80 \%$ of the population is destined for a certain point of life to an entire low back pain. It affects men and women equally; it occurs more often between 30 and 50 years of age; it involves very high individual and social costs, in terms of diagnostic analyses and treatments, reduction in productivity and capacity to carry out daily activities. Over $95 \%$ of the problems have a mechanical cause underlying low back pain. The most common causes are related the health status (Tiziana et al., 2017, Gaetano, 2016, Altavilla, 2014) and the degenerative processes related to eternity in the intervertebral discs and in the facet joints. It is a common reason for absence from work and for seeking medical treatment. It can be uncomfortable and debilitating. Pain in the upper back may be due to disorders of spine inflammation (Wilson, Cassar-Pullicino, 2017). Back pain can affect people of any age, for different reasons. People get older, the chance of developing lower back pain increases, due to factors such as motor performance in particular period and decrease of performance (Delia et al., 2019, Forte et al., 2019, Forte, Altavilla, 2018). Furthermore the disabled people and the athletes with disability have the same problem for the characteristic physiological adaptation to training (Pisapia et al, 2019, Martino et al., 2019, Severino et al., 2019, Pisapia, D'Isanto, 2018). The aim is, through a survey with a questionnaire, to highlight the differences between subjects who practice physical activity, non-practicing and subjects who attend a postural back gymnastics course.

\section{METHODS}

A comparative survey was conducted, through a structured questionnaire, with the aim of assessing the health status of the spine, in particular on the risk factors that may contribute to the onset of the common "back pain". The survey is defined as comparative because the main objective is to compare the differences between three types of subjects (people who practice physical activity, sedentary subjects and finally people who follow a course in postural gymnastics) towards the onset of pain back analysing: age, working methods, intensity, variation, onset and location of subjects' pain. The questionnaire was the instrument for measuring information on the phenomenon. It was realized through multiple choice questions, with a single open-ended question asking, for those who practiced physical activity, the activity they practiced. The methodology used for the realization of the questionnaire was aimed at highlighting, in broad terms, the different causes that cause back pain by first analysing the risk factors:

- $\quad$ Posture taken during the working day: the profession of the subject and his usual working posture are important news for understanding the onset of pain (he works sitting, standing, lifting weights);

- Influence of accidents and previous traumas: such as cervical whiplash or vertebral fractures, trauma to the lower limbs can affect the correct use of the spine;

- $\quad$ Practiced motor and sports activities: in particular the correlation between sport practiced and work activity is assessed;

and: 
- $\quad$ The intensity of pain;

- The onset of pain;

- Variations of pain: if the pain increases or decreases;

- $\quad$ Localization of pain: which region of the spine is affected by pain.

\section{RESULTS}

The aim of the survey was to highlight the differences on the onset of back pain between different categories of subjects. It follows that the results show that in subjects who practice physical activity the onset and intensity of the back is lower than those who do not practice physical activity and therefore live a sedentary life. Also, we want to demonstrate how the causes of back pain are affected by various causes that cause muscle and joint pain, especially if they are located in the spine such as cervical (Kapandji, 2011), dorsal and lumbar pain: long-term wrong postures (professional activity, guide of 'car, television, reading, etc. ..) incorrect movements, efforts carried out in incongruous positions can contribute to the onset of pain as an incorrect posture can lead to greater loads on vertebrae and joints, postural rigidity due to psychic stress can lead to assuming contracted attitudes, the poor tone of the muscles due to sedentarism and, therefore, the loss of muscular strength, are all probable and valid causes of the onset of cervical, dorsal and lumbar pain.

To firmly support it are professionals of the "Finnish Institute of Occupational Health" in Helsinki, who conducted a thorough study on the subject, drawing the conclusion that a correct physical activity reduces the risk of finding oneself with a chronic disorder for percentages ranging from 11 to $16 \%$.

The answers to the questionnaire were the following:

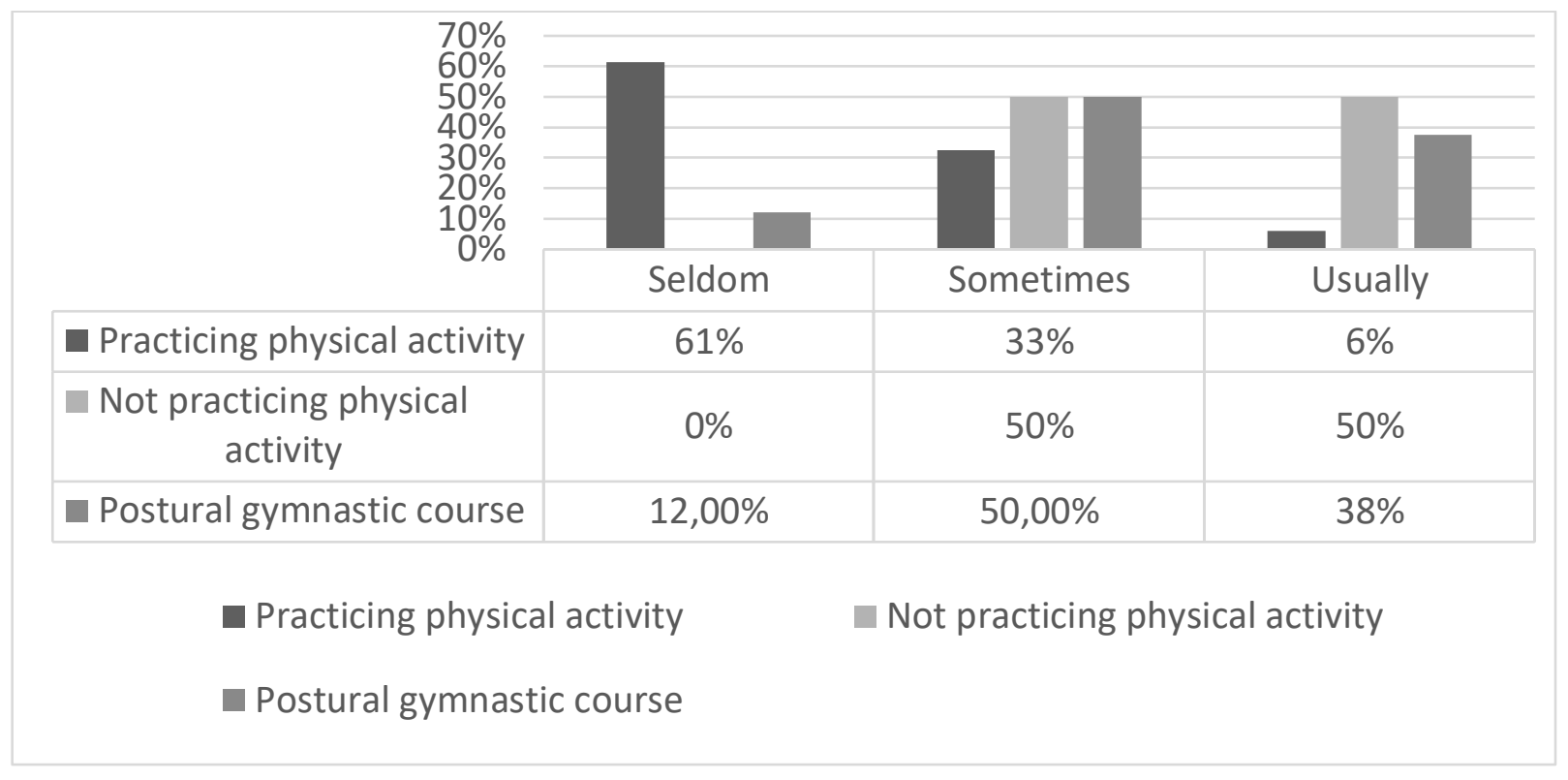

Figure 1. Results to the question "Do you suffer from back pain?"

The $61 \%$ of subjects who practice physical activity rarely suffer from back pain unlike $0 \%$ of those who do not practice activities; while the highest percentage of subjects (50\% against $6 \%$ ) who usually suffer from it is those who do not practice physical activity. It follows that the subjects subjected to the test, and who practice physical activity, suffer from back pain rarely, only a small percentage usually suffer from it. 


\begin{tabular}{|c|c|c|c|c|}
\hline \multirow{2}{*}{$\begin{array}{l}80 \% \\
70 \% \\
60 \% \\
50 \% \\
40 \% \\
30 \% \\
20 \% \\
10 \% \\
0 \%\end{array}$} & & & & \\
\hline & I do nothing & I take drugs & $\begin{array}{l}\text { I perform } \\
\text { postural } \\
\text { exercises }\end{array}$ & $\begin{array}{l}\text { I apply to } \\
\text { treatments/ } \\
\text { massages }\end{array}$ \\
\hline practicing physical activity & $38 \%$ & $10 \%$ & $38 \%$ & $14 \%$ \\
\hline $\begin{array}{l}\text { Not practicing physical } \\
\text { activity }\end{array}$ & $33 \%$ & $67 \%$ & $0 \%$ & $0 \%$ \\
\hline Postural gymnastic course & $12,50 \%$ & $0,00 \%$ & $75 \%$ & $25 \%$ \\
\hline $\begin{array}{l}\text { - practicing physic } \\
\text { Postural gymnas }\end{array}$ & $\begin{array}{l}\text { cal activity } \\
\text { stic course }\end{array}$ & Not practic & physical act & \\
\hline
\end{tabular}

Figure 2. Results to the question "If the intensity of pain is persistent over time, how do you help yourself?"

How do the three categories react to pain? With the question "If the intensity of pain is persistent over time, how do you help yourself?" It was shown that $67 \%$ of non-practitioners take drugs, against $38 \%$ of those who practice and $75 \%$ of those who follow the postural course prefers to help themselves with the help of postural exercises. A good percentage of respondents also said: I do nothing.

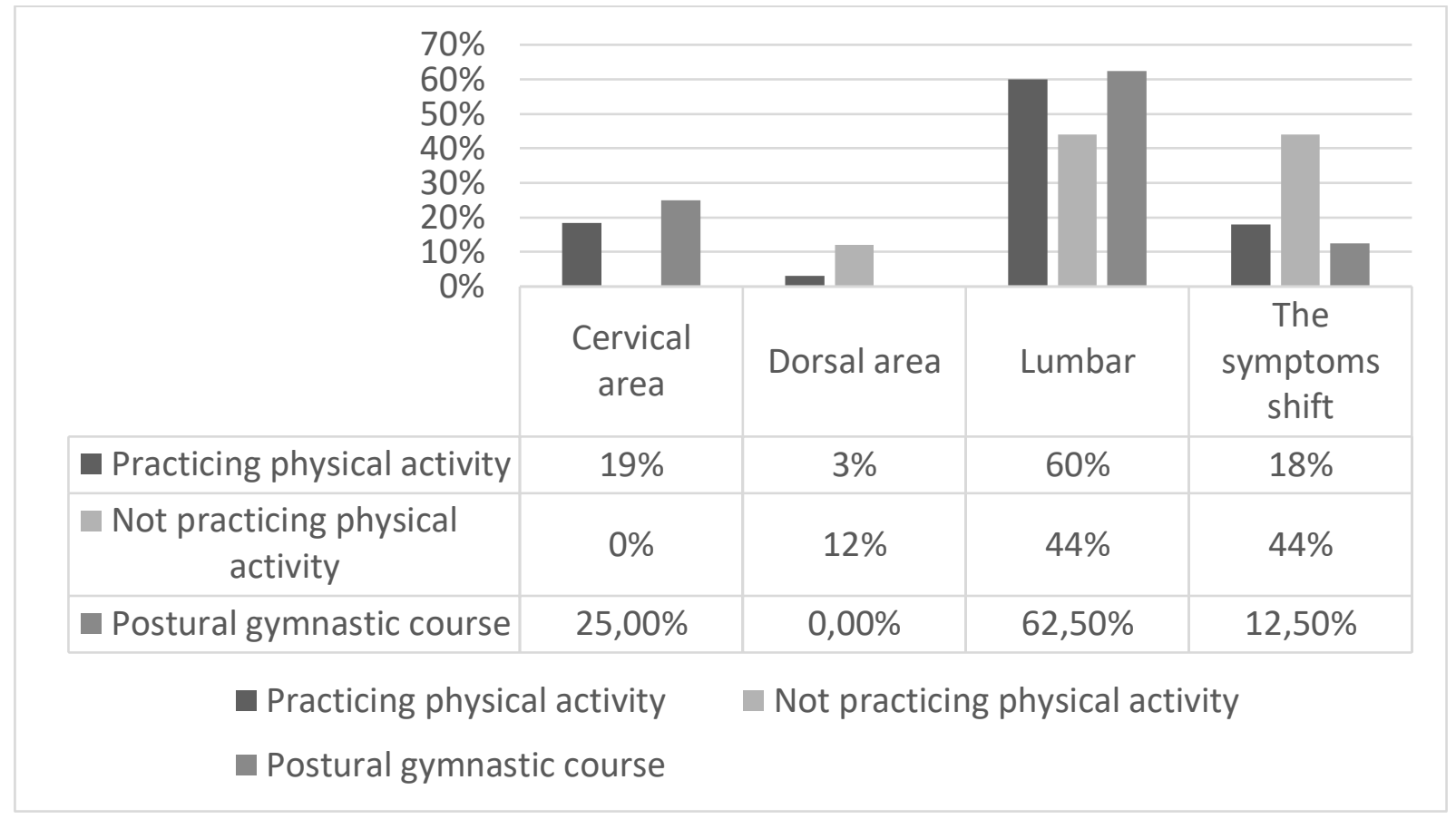

Figure 3. Results to the question "What is the area of the spine where you feel the symptoms more?" 
Without a doubt the area most subject to pain is the lumbar area and in the minority also the cervical area.

\section{DISCUSSION}

This study has tried to detect and confirm a theory already present in the scientific world and widely demonstrated: how physical activity can be of great help in the treatment of annoying muscle pains. The answers to the questionnaire showed that the features of the spine most subject to stress during daily activities are the cervical and lumbar ones due to some positions taken for a prolonged time and after having suffered an effort in an incongruous position. The fixed positions should be physiologically correct and interrupted frequently, assuming positions of relaxation of the cervical and dorsal tract and possibly performing simple exercises of joint mobility and muscle stretching. Above all, the lumbar tract is particularly stressed because almost all the human trunk load on it. Night rest, sometimes underestimated, can contribute to the onset of pain. It is important that the mattress and the pillow must be such as to allow the spine to maintain its physiological curves. For example, a pillow that is too high or too low, for those who sleep in lateral decubitus, can easily cause pain in the cervical vertebrae and the head. At night, however, if the rest takes place in appropriate conditions, a reduction in pain should occur. In fact, according to Alf Nachemson's (1976) studies in the supine position the load on the third disk of the lumbar tract is equal to $25 \mathrm{~kg}$ against $75 \mathrm{~kg}$ in lateral decubitus position. Kapandij (1974) also showed that nocturnal rest favours recovery: with constant load during daylight hours dehydration occurs and the intervertebral disc thickness decreases. During the night hours, with the decrease in pressure on the column, the reverse process takes place, the disc rehydrates and recovers its thickness. It is therefore essential to sleep a sufficient number of hours on a valid bed to allow our disks to regain their original thickness and to maintain their efficiency and elasticity. In most cases there is an increase in symptoms when standing and a reduction in a sitting position therefore gives an indication to favour flexion exercises.

\section{CONCLUSIONS}

The survey showed an interesting data on how the sample prefers to help when the intensity of pain is persistent. Obviously, the majority of those who follow a course in postural gymnastics have performed postural exercises. The substantial difference was registered between those who practice activities and not those who do not. The first provide for the execution of exercises while the others prefer to the use of drugs such as painkillers or apply patches. These results are consistent with the expectations initially expressed in the paper, according to which sport is the most powerful medicine there is. However, physical exercise is useful from a therapeutic point of view only if carried out with a constant method and frequency, otherwise it is more difficult to benefit from it. If you have always led a sedentary life it is good to start with something "light", to gradually move on to more "demanding" exercises.

The present study complements the already existing literature concerning the correlation between physical activity and back pain, as previous studies had already provided scientific evidence. However, it is important to keep in mind that this research has focused on the main risk factors that affect the onset of back pain and how it can be limited through exercise.

\section{REFERENCES}

Altavilla, G., Di Tore, P.A. (2016) Physical education during the first school cycle: A brief social psychopedagogical summary, Journal of Physical Education and Sport, 16 (2), art. no. 55, pp. 340-344.

Altavilla, G. (2014) Effects of the practice of muscle stretching, Sport Science, 7 (1), pp. 66-67. 
Avman, M.A., Osmotherly, P.G., Snodgrass, S., Rivett, D.A. (2019) Is there an association between hip range of motion and nonspecific low back pain? A systematic review Musculoskeletal Science and Practice, 42, pp. 38-51. https://doi.org/10.1016/i.msksp.2019.03.002

Ceciliani, A. (2018) From the embodied cognition to the embodied education in the physical and sports sciences, Encyclopaideia, 22 (51), pp. 11-24.

Ceciliani, A., Di Carlo, M., Tentoni, C. (2005). Mental process learning Medicina dello Sport, 58 (1), pp. 43-52.

D'Elia, F. (2019). The training of physical education teacher in primary school. Journal of Human Sport and Exercise, 14(1proc), S100-S104. https://doi.org/10.14198/ihse.2019.14.Proc1.12

D'Elia, F., D'Isanto, T., \& Altavilla, G. (2019). Training and performance in the transition period. Journal of Human Sport and Exercise, 14(2proc), S258-S262. https://doi.org/10.14198/ihse.2019.14.Proc2.15

D'Isanto, T. (2019) Physical and sport education between Italian academic system and European Research Council structure panel, Journal of Human Sport and Exercise, 14, pp. S66-S76. https://doi.org/10.14198/ihse.2019.14.proc1.08

D'Isanto, T. (2016) Pedagogical value of the body and physical activity in childhood, Sport Science, 9, pp. 13-18.

Di Tore, P.A., Schiavo, R., D'Isanto, T. (2016) Physical education, motor control and motor learning: Theoretical paradigms and teaching practices from kindergarten to high school, Journal of Physical Education and Sport, 16 (4), art. no. 205, pp. 1293-1297.

Fewster, K.M., Riddell, M.F., Gallagher, K.M., Callaghan, J.P. (2019) Does proactive cyclic usage of a footrest prevent the development of standing induced low back pain? Human Movement Science, 66, pp. 84-90. https://doi.org/10.1016/j.humov.2019.03.013

Forte, D., Ceciliani, A., Izzo, R., Altavilla, G. (2019) Transition period: Pilot study on performance reduction of ability to jump in volleyball, Journal of Human Sport and Exercise, 14 (Proc2), pp. S221S227. https://doi.org/10.14198//hse.2019.14.proc2.09

Forte, D., Altavilla, G. (2018) Preliminary correlation between anthropometric and performance data in volleyball about the transition period, Journal of Physical Education and Sport, 18, art. no. 296, pp. 1994-1998.

Gaetano, A. (2016) Relationship between physical inactivity and effects on individual health status, Journal of Physical Education and Sport, 16, pp. 1069-1074.

Martino, L., Fonzo, E., Cassese, F.P., D'isanto, T. (2019) Principles of adaptation of the rules for disabled athletes for an inclusion sport, Journal of Human Sport and Exercise, 14 (Proc2), pp. S215-S220. https://doi.org/10.14198/ihse.2019.14.proc2.08

Gallagher, K.M., Payne, M., Daniels, B., Caldwell, A.R., Ganio, M.S. Walking breaks can reduce prolonged standing induced low back pain (2019) Human Movement Science, 66, pp. 31-37.

Murillo, C., Falla, D., Sanderson, A., Rushton, A., Heneghan, N.R. (2019) Shear wave elastography investigation of multifidus stiffness in individuals with low back pain Journal of Electromyography and Kinesiology, 47, pp. 19-24. https://doi.org/10.1016/.humov.2019.03.012

Nachemson A., (1976) The Lumber Spine - An Orthopedic Challenge: Spine 1:59 - 71, March.

Kapandji, A.I. (2011) Anatomia Funzionale, Monduzzi Editoriale.

Pisapia, F., D'Isanto, T. (2018) Inclusive methods of adaptive training in sprints: A theoretical preliminary study, Journal of Physical Education and Sport, 18, art. no. 316, pp. 2101-2105.

Pisapia, F., Federici, A., Valentini, M., D'isanto, T. (2019) Pilot study on sprint training methods in different types of athletes, Journal of Human Sport and Exercise, 14 (Proc2), pp. S189-S197. https://doi.org/10.14198/ihse.2019.14.proc2.05 
Raiola, G., D'elia, F., Altavilla, G. (2018) Physical activity and sports sciences between European Research Council and academic disciplines in Italy, Journal of Human Sport and Exercise, 13, pp. S283-S295. https://doi.org/10.14198/ihse.2018.13.proc2.13

Sanseviero, I., Cassese, F.P., Fonzo, E., Altavilla, G., D'elia, F. (2019) Study on the master's degree in sciences of sports evaluation and sport for disabled at the University of Salerno, Italy, Journal of

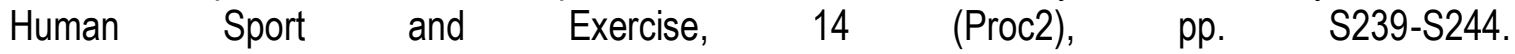
https://doi.org/10.14198/ihse.2019.14.proc2.12

Severino, N.C., Cassese, F.P., Ceciliani, A., D'elia, F., Di Tore, A.P. (2019) Psychophysical benefits of recreational five-a-side football, Journal of Human Sport and Exercise, 14 (Proc2), pp. S206-S214. https://doi.org/10.14198//hse.2019.14.proc2.07

Tiziana, D., Antonetta, M., Gaetano, A. (2017) Health and physical activity, Sport Science, 10 (1), pp. 100-105.

Valentini, M., Riccardi, F., Raiola, G., Federici, A. (2018) Educational research: Motor area and relational area during children's personality development, Journal of Physical Education and Sport, 18, art. no. 327, pp. 2157-2174.

Wilson, D.J., Cassar-Pullicino, V. (2017) Spine degeneration and inflammation Musculoskeletal Diseases 2017-2020: Diagnostic Imaging, pp. 215-224. https://doi.org/10.1007/978-3-319-54018-4_20

Zhou, F., Zhao, Y., Zhu, L., Jiang, J., Huang, M., Zhang, Y., Zhuang, Y., Gong, H. (2019) Compressing the lumbar nerve root changes the frequency-associated cerebral amplitude of fluctuations in patients with low back/leg pain Scientific Reports, 9 (1). https://doi.org/10.1038/s41598-019-38721$\underline{5}$

\section{(9) $(\mathbb{Q} \Theta \Theta$}

This work is licensed under a Attribution-NonCommercial-NoDerivatives 4.0 International (CC BY-NC-ND 4.0). 